\title{
The maintenance of matching behavior when contrast occurs in multiple concurrent concurrent schedules of reinforcement
}

\author{
A. J. M. MARCATTILIO and RALPH W. RICHARDS \\ Colorado State University, Fort Collins, Colorado 80521
}

\begin{abstract}
Pigeons were trained on a multiple schedule of reinforcement in which each component was a concurrent schedule. The concurrent schedules were programmed by the changeover-key procedure. The primary purpose was to determine if the relative behavior allocated to two response alternatives is affected when absolute changes in these behaviors occur; i.e., to determine if matching is affected when positive behavioral contrast occurs. Results showed that (1) relative behavior in the unaltered component of the multiple schedule is not disrupted when positive contrast occurs in that component, (2) positive contrast occurred when the overall frequency of reinforcement in the reinforcement-correlated component(s) was high, but not when it was low, (3) changeover behavior was susceptible to positive contrast effects, and (4) changeover contrast and food-key contrast are independent phenomena.
\end{abstract}

Studies of choice behavior in concurrent schedules of reinforcement have shown that there is a simple relationship between the subject's response rates and obtained reinforcement rates. This relationship, called the matching law (Herrnstein, 1961, 1970), states that pigeons' relative rate of responding in one component of the concurrent schedule matches the relative rate of reinforcement obtained in that component. Baum and Rachlin (1969) have suggested that this relationship may be best expressed as the proportional quantity:

$$
\frac{P_{1}}{P_{2}}=K \frac{r_{1}}{r_{2}}
$$

where $P_{1}$ and $P_{2}$ and the total number of responses emitted during the first and second components, respectively, $r_{1}$ and $r_{2}$ are the total number of reinforcements obtained in the first and second components, respectively, and $K$ is a constant describing the bias between the components.

A great deal of research has documented the accuracy of the matching law, and shown that matching does occur when parameters of reinforcement such as frequency, magnitude, delay, and quality are manipulated (see de Villiers, 1977, for review). Relatively little research, however, has been concerned with

This paper is based on a dissertation submitted by the first author to the Department of Psychology, Colorado State University, in partial fulfillment of the requirements for the PhD degree. The authors wish to thank Peter Killeen and Steve Hanson for their insightful comments on earlier portions of this manuscript. Reprints may be obtained from the first aurthor, who is now at Cambridge State Hospital, Cambridge, Minnesota 55008. testing some of the more discerning implications of the analysis. For example, one inference common to various forms of the matching relationship (e.g., Baum \& Rachlin, 1969; Herrnstein, 1970) is that absolute and relative behaviors are independent of each other (i.e., one may change while the other remains constant). This notion has been confirmed in a number of situations (see Herrnstein, 1961; Holz, 1968; McSweeny, 1975, 1977; Wald \& Cheney, 1975), but such research has been quite limited. Since the viability of any theory rests upon its consistency and applicability across as many conditions as possible, the focus of the present study was to test further the independent nature of absolute and relative rate of response in a manner different from that of past research. This was accomplished by modifying the prototypical paradigm that produces behavioral contrast in simple multiple schedules. In the prototypical paradigm, a change from multiple variable-interval variable-interval (mult VI VI) reinforcement to multiple variable-interval extinction (mult VI EXT) reinforcement results in a decrease in response rate during the second component because responding is no longer reinforced, while response rate in the first component increases above the baseline level even though the reinforcement contingencies associated with that component have not been changed (see Reynolds, 1961). Specifically, subjects in the present study were exposed to a multiple schedule in which each component was a concurrent schedule of reinforcement. With a change from conc VI VI reinforcement to conc EXT EXT in one component of the multiple schedule, it was expected that absolute rate of responding to each response alternative in the unaltered component would increase (i.e., contrast), while the relative rate (i.e., 
matching) of behavior allocated to these alternatives would remain invariant.

One additional dependent variable that may be examined in concurrent schedules is the number of times subjects change from one component to another. Research has shown, for example, that the frequency of changeovers between components is affected by manipulating various contingencies associated with those components (see Brownstein \& Pliskoff, 1968; Herrnstein, 1961; Pliskoff \& Green, 1972; Shull \& Pliskoff, 1967, 1971; Todorov, 1971). Moreover, two investigations (Catania, 1961; Marcattilio \& Richards, 1976) have reported data which suggests that the frequency of changeovers between components may also be affected by manipulating the reinforcement contingencies associated with other stimuli. That is, changeover behavior may be subject to the contrast phenomenon. It should be pointed out, however, that these previous investigations of changeover contrast have revealed either minimal (Catania, 1961) or somewhat inconsistent (Marcattilio \& Richards, 1976) effects. One possible reason for these inconclusive findings is that both of these studies employed the two-key concurrent procedure, in which the changeover response is not clearly defined. The changeoverkey procedure (Findley, 1958) for arranging concurrent schedules may be more sensitive to changeover contrast because it more explicitly defines the changeover behavior, that is, a discrete peck on the changeover key (see Catania, 1966). Consequently, the second purpose of the present study was to determine whether or not contrast with regard to changeover behavior is, indeed, a robust phenomenon.

Because no previous research has demonstrated positive behavioral contrast in a multiple concurrent concurrent (mult conc conc) schedule in which concurrent schedules are arranged according to the changeover-key procedure, two experiments were conducted. Experiment 1 was designed to assess whether or not contrast can be obtained in a mult conc conc schedule programmed in a manner as analogous as possible to a simple multiple schedule (i.e., equal concurrent reinforcement densities). Based on the findings of Experiment 1, Experiment 2 was designed to assess the primary purpose of the present research, that is, whether or not relative behavior is disrupted when contrast occurs.

\section{EXPERIMENT 1}

\section{Method}

Subjects. Four adult female White Carneaux pigeons, obtained from the Palmetto Pigeon Plant, served as subjects. The birds were experimentally naive and maintained at approximately $80 \%$ of their free-feeding weights.

Apparatus. A Lehigh Valley Electronics three-key pigeon chamber with internal dimensions of $31.1 \times 35.6 \times 35.6 \mathrm{~cm}$ was the experimental space. Only the center key (food key) and right key (changeover key), measuring $8.5 \mathrm{~cm}$ center-to-center, were employed. The left key was dark and nonfunctional. Sylvania 24ESB light bulbs illuminated the food key with a purple, red, green, blue, or yellow light and the changeover key with a white light. A force of approximately $.12 \mathrm{~N}$ was required to operate each key. A CM 1820 light bulb, mounted $5 \mathrm{~cm}$ above the food key and shielded towards the ceiling, provided general illumination in the chamber. Approximately $9 \mathrm{~cm}$ below the food key was a $5.8 \times 5.0 \mathrm{~cm}$ opening which provided access to occasional presentations of the mixed grain reinforcer. The duration of the reinforcer was $2 \mathrm{sec}$, except during shaping when it was manually controlled; the timing of this interval began when the bird placed its head into the magazine opening and interrupted a light beam focused on a photocell. The chamber's fan masked extraneous noise.

Standard electromechanical programming and recording equipment were housed in another room.

Procedure. During preliminary training, the food key was illuminated purple, the houselight was on, and the changeover key was dark and nonfunctional. After habituation to the apparatus, keypecking was shaped by the method of successive approximations. This was followed by 6 additional days of pretraining in which the frequency of reinforcement was gradually reduced until a VI 60-sec schedule was attained.

The birds were then given daily sessions of mult (conc VI VI) (conc VI VI) reinforcement. Specifically, the birds were exposed to a two-component concurrent schedule, associated with red and green key lights, that alternated with another two-component concurrent schedule, associated with yellow and blue key lights. The concurrent schedules were arranged according to the Findley (1958) changeover-key procedure. That is, both components of the concurrent schedule operated simultaneously, and each was associated with a different color on the food key. A peck on the changeover key changed the color and schedule assignment on the food key.

During each session, which began and ended in complete darkness, each component of the multiple schedule was presented 30 times. Each component of the concurrent schedule initiated the presentation 15 times. The order of presentations was mixed with two additional restrictions: (1) There were no more than three successive presentations of the same component of the multiple schedule, and (2) there were no more than two successive occasions in which the same component of the concurrent schedule initiated the presentation. A new sequence of mixed presentations was generated every 25 to 36 days. Presentations of each component of the multiple schedule were $1 \mathrm{~min}$ in duration (excluding reinforcement periods) and were separated by a 1-sec blackout. During reinforcement, the hopper, houselight, and changeover key were illuminated, but the food key was dark. Pecks on the food key and changeover key were nonfunctional during reinforcement. Reinforcements set up, but not collected, at the end of a component were carried over to the next presentation of that component.

To ensure that pecking during one component of the concurrent schedule did not come under the control of the schedule associated with the other component, a 2-sec changeover delay (COD; Herrnstein, 1961) was employed. The COD (timed from a peck on the changeover key) specifies a minimum temporal interval before a peck on the food key can be followed by a reinforcer. If successive pecks occurred on the changeover key, the 2-sec COD period began anew, and the component assigned to the food key was changed accordingly.

Table 1 shows the conditions, the number of phases in each condition, and the schedule of reinforcement associated with each stimulus during each phase. It is important to note that the reinforcement contingencies associated with red and green never changed within a condition. During Phase 1 (the baseline phase of each condition), the birds received a maximum of 50 sessions. If a bird's responding stabilized prior to this (but after a minimum of 25 sessions), it was advanced to the next phase. 
Table 1

Condition, Phase, and Schedule of Reinforcement Associated With Each Stimulus During That Phase

\begin{tabular}{|c|c|c|c|c|c|}
\hline \multirow{4}{*}{$\begin{array}{c}\text { Condi- } \\
\text { tion }\end{array}$} & \multirow[b]{4}{*}{ Phase } & \multicolumn{4}{|c|}{ Component of Multiple Schedule } \\
\hline & & \multicolumn{2}{|c|}{ Unaltered } & \multicolumn{2}{|c|}{ Altered } \\
\hline & & \multicolumn{2}{|c|}{ Key Color } & \multicolumn{2}{|c|}{ Key Color } \\
\hline & & Red & Green & Yellow & Blue \\
\hline 1 & $\begin{array}{l}1 \\
2 \\
3\end{array}$ & $\begin{array}{ll}\text { VI } 2.4 \\
\text { VI } 2.4 \\
\text { VI } 2.4\end{array}$ & $\begin{array}{l}\text { VI } 2.4 \\
\text { VI } 2.4 \\
\text { VI } 2.4\end{array}$ & $\begin{array}{l}\text { VI } 2.4 \\
\text { EXT } \\
\text { VI } 2.4\end{array}$ & $\begin{array}{l}\text { VI } 2.4 \\
\text { EXT } \\
\text { VI } 2.4\end{array}$ \\
\hline $2 A$ & $\begin{array}{l}1 \\
2 \\
3\end{array}$ & $\begin{array}{l}\text { VI } 4.8 \\
\text { VI } 4.8 \\
\text { VI } 4.8\end{array}$ & $\begin{array}{l}\text { VI } 4.8 \\
\text { VI } 4.8 \\
\text { VI } 4.8\end{array}$ & $\begin{array}{l}\text { VI } 4.8 \\
\text { EXT } \\
\text { VI } 4.8\end{array}$ & $\begin{array}{l}\text { VI } 4.8 \\
\text { EXT } \\
\text { VI } 4.8\end{array}$ \\
\hline $3 \mathrm{~A}$ & $\begin{array}{l}1 \\
2 \\
3\end{array}$ & $\begin{array}{ll}\text { VI } 2.4 \\
\text { VI } 2.4 \\
\text { VI } 2.4\end{array}$ & $\begin{array}{ll}\text { VI } 2.4 \\
\text { VI } 2.4 \\
\text { VI } 2.4\end{array}$ & $\begin{array}{l}\text { VI } 2.4 \\
\text { EXT } \\
\text { VI } 2.4\end{array}$ & $\begin{array}{l}\text { VI } 2.4 \\
\text { EXT } \\
\text { VI } 2.4\end{array}$ \\
\hline
\end{tabular}

Note-The values of all VI schedules are in minutes and are constructed from a constant probability progression (Catania \& Reynolds, 1968). Key color refers to the color of the food key during each component of the concurrent schedules. The notations $2 A$ and $3 A$ are used to distinguish these conditions from the second and third conditions (labeled $2 B$ and $3 B$ ) of Experiment 2 . Condition 1 involved the same reinforcement contingencies in both experiments.

When the response rates for each of five consecutive sessions deviated $10 \%$ or less from the mean response rate for those five sessions, responding was considered stable. Twenty-five sessions were given in all other phases.

\section{Results}

Before proceeding with a description of the data obtained in Experiment 1, some general comments are in order. First of all, the figures showing the rates of responding on the food key and changeover key during the unaltered component of the multiple schedule contain the average rate of response during the last 15 sessions given in each phase during each condition. Second, food-key and changeover-key response rates during the altered component of the multiple schedule were very orderly in that they (1) did not differ from response rates in the unaltered component during each Phase 1, (2) decreased to low levels when extinction was programmed during each Phase 2, and (3) returned to baseline levels in each Phase 3 when the conc VI VI schedule was reinstated. Consequently, no further description is given regarding these data. Third, because the stability criterion was obtained in only 3 (of a possible 12) instances, t-test analyses were conducted comparing the last 15 sessions of Phase 1 with the last 15 sessions of Phase 2, and the last 15 session of Phase 2 with the last 15 sessions of Phase 3 within conditions for each bird. Of the 48 pairwise comparisons $(\mathrm{df}=28$ in each comparison) assessing changes in responding on the food key and the changeover key, 34 were significant well beyond the .001 level, 4 were significant beyond the .01 level, 1 was significant beyond the .02 level, and 2 were significant beyond the .05 level; the 7 remaining comparisons revealed nonsignificant effects ( $p>.10$ or .20 ). For purposes of brevity and clarity, description and discussion of changes in responding noted below are put simply in terms of whether or not the changes were significant. Finally, the schedule of reinforcement associated with the unaltered component of the multiple schedule during each condition is noted at the top of each figure.

Food-key responding in the unaltered component of the multiple schedule. Figure 1 shows the average overall rates of responding on the food key for each bird. In Condition 1, the subjects were trained on a conc VI 2.4-min VI 2.4-min schedule in the unaltered component of the multiple schedule. During the final sessions of Phase 1 of this condition, none of the birds showed any systematic increases in responding; in some cases downward trends were evident (these session to session changes are not shown). In Phase 2, all four birds significantly increased their responding. In Phase 3, there was a significant decrease in responding to a level slightly above baseline (B-1900) or slightly below (remaining three birds).

In Condition $2 \mathrm{~A}$, the subjects were exposed to a conc VI 4.8-min VI 4.8-min schedule in the unaltered component of the multiple schedule. Responding was again fairly stable for three of the birds, although, B-2855 showed a slight increase during the terminal sessions of Phase 1. In Phase 2, three birds showed a significant increase in unaltered component responding while one bird (B-1900) showed a nonsignificant decrease in responding. In Phase 3, B-2855 and B-1900 significantly increased their responding above Phase 2 levels while B-716 showed a significant decrease; B-4310 showed no change relative to the terminal sessions of Phase 2.

Because the experimental conditions had unreliable effects during Condition $2 \mathrm{~A}$, it was deemed necessary to conduct a third condition to determine if responding in the unaltered component became insensitive to changes in the reinforcement contingencies associated with the altered component. Given such, subjects were again trained on a conc VI 2.4-min VI 2.4-min schedule in the unaltered component of the multiple schedule during Condition 3A. During the final sessions of Phase 1 , all birds showed very stable responding. In Phase 2 , three birds showed a significant increase in responding; this was followed by a significant decrease back towards baseline in Phase 3. B-4310, on the other hand, showed no change in responding in Phase 2 but a significant increase in Phase 3.

Changeover-key responding during the unaltered component of the multiple schedule. Figure 2 shows the average rate of changeovers for each bird during the last 15 sessions of each phase. During Condition 1, a conc VI 2.4-min VI 2.4-min schedule was programmed in the unaltered component. During the baseline phase of this condition, changeover rates 


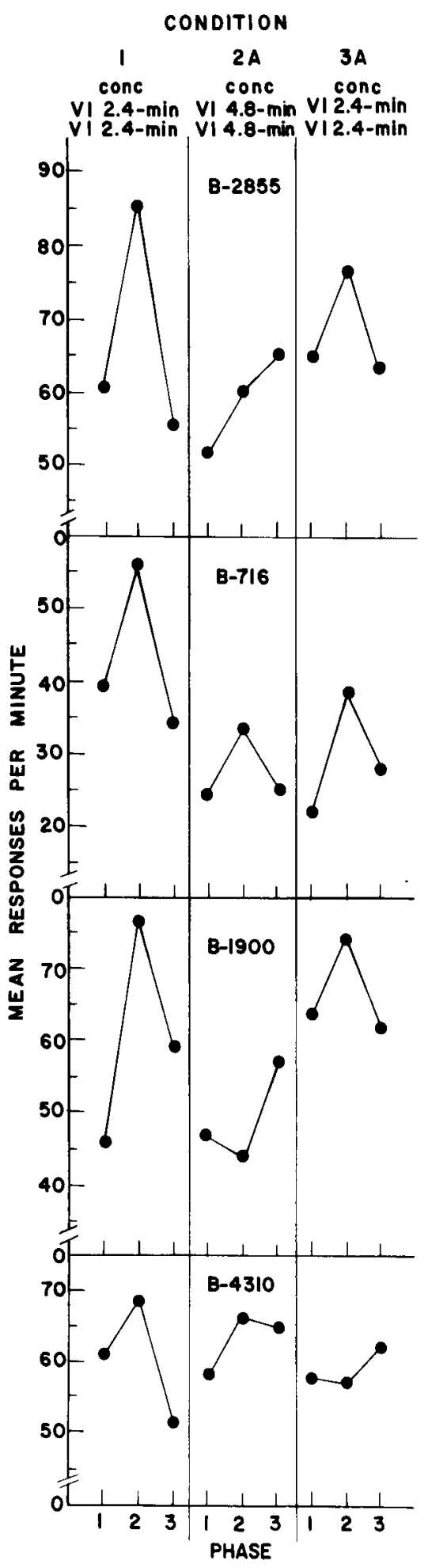

Figure 1. Average overall rate of responding on the food key during the unaltered component of the multiple schedule during the last 15 sessions of each phase for each bird. The schedule of reinforcement during the unaltered component is noted for each condition.

were somewhat variable, but only B-4310 exhibited a slight increasing trend during the last few sessions. In Phase 2 , all birds significantly increased their change- over rates above baseline levels and subsequently exhibited a significant decrease back to baseline levels during Phase 3.

In Condition 2A, the subjects were exposed to a conc VI 4.8-min VI 4.8-min schedule in the unaltered component of the multiple schedule. In Phase 1, changeover rates were quite variable, but no systematic trends were evident prior to the experimental manipulation. During Phase 2, three birds showed a significant increase in changeover responding, but only one of these (B-4310) significantly decreased its responding back to baseline; the remaining bird (B1900 ) exhibited no significant changes in responding across the three phases of this condition.

In Condition 3A, a conc VI 2.4-min VI 2.4-min schedule was programmed in the unaltered component. Three birds exhibited fairly stable responding throughout the last 15 sessions of Phase 1, while one bird (B-2855) showed a slight decreasing trend. In Phase 2, all four birds significantly increased their changeover rates above baseline levels which was subsequently followed by a significant decrease back to baseline during Phase 3 .

\section{Discussion}

Experiment 1 examined behavioral contrast effects in a mult conc conc schedule in which the concurrent schedules were programmed according to the changeover-key procedure. Results showed that contrast can be obtained in such a schedule but only under certain conditions. During Condition 1, a conc VI 2.4-min VI 2.4-min schedule was programmed in each component (except the altered component during Phase 2) of the multiple schedule, and positive behavioral contrast (i.e., a significant increase in unaltered component responding during Phase 2 followed by a significant decrease during Phase 3 ) was obtained in all four cases. Conversely, when a conc VI 4.8-min VI 4.8-min schedule was programmed during Condition $2 \mathrm{~A}$, contrast was obtained in only one of four cases. The results of Condition 1, it should be noted, seem to be reliable, since positive contrast was again obtained in a majority of the cases when behavior under a conc VI 2.4-min VI 2.4-min schedule was reexamined during Condition $3 \mathrm{~A}$. Furthermore, contrast effects with regard to changeover behavior reliably occurred only under those conditions in which food-key contrast was obtained (i.e., Conditions 1 and $3 \mathrm{~A}$, but not $2 \mathrm{~A}$ ). These findings are similar to those obtained in previous research conducted by the authors (Marcattilio \& Richards, 1976) in which a two-key concurrent schedule was programmed in each component of the multiple schedule, and a between-groups design was utilized. Because behavioral contrast has been reported in other types of multiple schedules arranging both high and low reinforcement frequencies (e.g., Bilbrey \& Winokur, 1974; Reynolds, 1963; Spealman \& Gollub, 1974; Wilton \& Gay, 1969), the data obtained under the present procedures have certain implications for several theories 


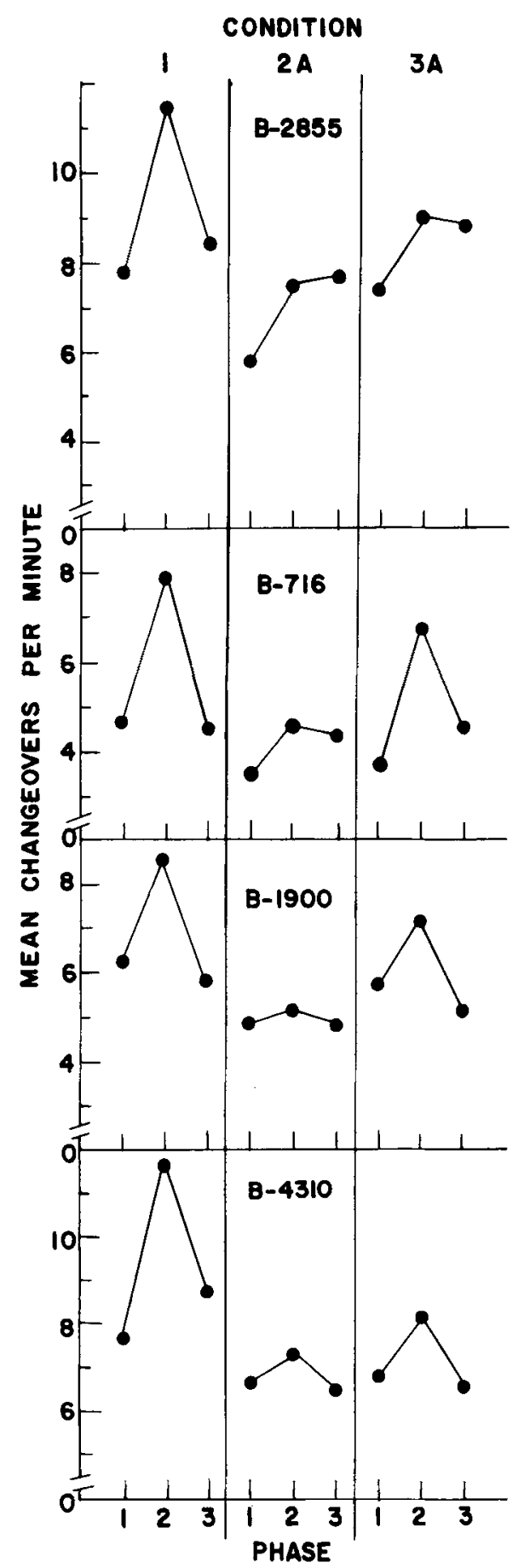

Figure 2. Average overall rate of responding on the changeover key during the unaitered component of the multiple schedule during the last $\mathbf{1 5}$ sessions of each phase for each bird.

of contrast. In order to explain the present findings, for example, additivity theory (Schwartz \& Gamzu, 1977) would have to say that extinction caused Pavlovian keypecks to occur and combine with operant keypecks to produce contrast in the unaltered component when the overall rate of reinforcement in that component is high, but not when it is low. Aversiveness theory (Bloomfield, 1969; Premack,
1969) would have to state that the change from highdensity reinforcement to extinction in the altered component was sufficiently aversive to produce contrast in the unaltered component, but the change from low reinforcement frequency to extinction was not. Terrace's (1972) emotionality theory would have to say that responding during the altered component was actively inhibited with the change from high reinforcement frequency to extinction (thus producing contrast in the unaltered component), but responding was passively inhibited with the change from low reinforcement frequency to extinction (thus attenuating potential contrast effects). Herrnstein's (1970) relative reinforcement theory would have to specify that either the interactive parameter $(\mathrm{m})$ or the rate of reinforcement for behavior other than keypecking $\left(r_{0}\right)$ did not remain constant across the three phases of Condition 2A, but did during Conditions 1 and $3 \mathrm{~A}$. Finally, the response competition hypothesis (Hinson \& Staddon, 1978) would have to postulate that changing the reinforcement contingencies in the altered component causes a reallocation of interim and terminal behaviors when reinforcement frequency is high, but not when it is low. Whatever process(es) causes contrast effects, it (they) apparently functions in mult conc conc schedules when the overall frequency of reinforcement in each component (except the altered component during Phase 2) is high (e.g., about 25 reinforcers per component per session, as in Conditions 1 and $3 \mathrm{~A}$ ) but not when they are low (e.g., about 12 reinforcers per component per session, as in Condition 2A).

While such specification of the underlying mechanism(s) responsible for these findings should be the goal of the future research, the primary purpose of the present study was to further evaluate the independent nature of absolute and relative strength of behavior, as mentioned earlier. Based on the findings of Experiment 1, Experiment 2 was designed to make this assessment. Specifically, birds in Experiment 2 were exposed to a mult conc conc schedule in which the overall rate of reinforcement in the component(s) associated with reinforcement was held at a high constant value (about 24 reinforcers per component per session), but different relative rates of reinforcement were associated with each response alternative in the component(s). Absolute response rates were then changed by the same experimental manipulations employed in Experiment 1.

\section{EXPERIMENT 2}

\section{Method}

Subjects. Four adult female White Carneaux pigeons obtained from the Palmetto Pigeon Plant served. These birds were also experimentally naive and maintained at approximately $80 \%$ of their free feeding weights.

Apparatus. The apparatus were the same as in Experiment 1.

Procedure. After shaping and pretraining in the same manner as Experiment 1, birds in Experiment 2 were given daily sessions of 
mult (conc VI VI) (conc VI VI) schedules of reinforcement. Since the birds in this experiment were naive, it was deemed appropriate to expose them to equal concurrent reinforcement densities during the first condition to ensure that positive contrast could be obtained in these subjects (this represents a partial replication of Experiment 1 while providing data regarding behavioral allocation with equal concurrent reinforcement densities). However, in ensuing conditions, unequal concurrent reinforcement densities were programmed as shown in Table 2 . In all other respects, the procedures used in this experiment were the same as in Experiment 1.

\section{Results}

As was the case earlier, some comments are in order before proceeding with a description of the data obtained in Experiment 2.

First of all, food key and changeover key responding during the altered component of the multiple schedule were again orderly, and similar to that obtained in Experiment 1 . Hence, these data will not be considered further. Second, as was the case in Experiment 1 , the stability criterion was attained in only a couple of cases ( 2 of 12 ). As a consequence, $t$-test analyses were again conducted on food-key and changeover-key responding, assessing differences in terminal performance across Phases 1 and 2 and Phases 2 and 3 of each condition for individual birds. Of the 48 pairwise comparisons $(\mathrm{df}=28$ in each comparison) conducted, 31 were significant well beyond the .001 level, 7 were significant at the .01 level, 2 were significant at the .02 level, 2 were significant at the .05 level, leaving 6 comparisons revealing nonsignificant effects $(\mathrm{p}>.10$ or .20$)$. As was the case earlier, the observed changes in behavior will be described in terms of whether or not they were statistically significant. Finally, while change-

Table 2

Condition, Phase, and Schedule of Reinforcement Associated With Each Stimulus During That Phase

\begin{tabular}{|c|c|c|c|c|c|}
\hline \multirow{4}{*}{$\begin{array}{c}\text { Condi- } \\
\text { tion }\end{array}$} & \multirow[b]{4}{*}{ Phase } & \multicolumn{4}{|c|}{ Component of Multiple Schedule } \\
\hline & & \multicolumn{2}{|c|}{ Unaltered } & \multicolumn{2}{|c|}{ Altered } \\
\hline & & \multicolumn{2}{|c|}{ Key Color } & \multicolumn{2}{|c|}{ Key Color } \\
\hline & & Red & Green & Yellow & Blue \\
\hline 1 & $\begin{array}{l}1 \\
2 \\
3\end{array}$ & $\begin{array}{l}\text { VI } 2.4 \\
\text { VI } 2.4 \\
\text { VI } 2.4\end{array}$ & $\begin{array}{l}\text { VI } 2.4 \\
\text { VI } 2.4 \\
\text { VI } 2.4\end{array}$ & $\begin{array}{l}\text { VI } 2.4 \\
\text { EXT } \\
\text { VI } 2.4\end{array}$ & $\begin{array}{l}\text { VI } 2.4 \\
\text { EXT } \\
\text { VI } 2.4\end{array}$ \\
\hline $2 B$ & $\begin{array}{l}1 \\
2 \\
3\end{array}$ & $\begin{array}{ll}\text { VI } 2 \\
\text { VI } 2 \\
\text { VI } 2\end{array}$ & $\begin{array}{l}\text { VI } 3 \\
\text { VI } 3 \\
\text { VI } 3\end{array}$ & $\begin{array}{l}\text { VI } 2 \\
\text { EXT } \\
\text { VI } 2\end{array}$ & $\begin{array}{l}\text { VI } 3 \\
\text { EXT } \\
\text { VI } 3\end{array}$ \\
\hline $3 B$ & $\begin{array}{l}1 \\
2 \\
3 \\
\end{array}$ & $\begin{array}{l}\text { VI } 1.5 \\
\text { VI } 1.5 \\
\text { VI } 1.5\end{array}$ & $\begin{array}{l}\text { VI } 6 \\
\text { VI } 6 \\
\text { VI } 6\end{array}$ & $\begin{array}{l}\text { VI } 1.5 \\
\text { EXT } \\
\text { VI } 1.5\end{array}$ & $\begin{array}{l}\text { VI } 6 \\
\text { EXT } \\
\text { VI } 6\end{array}$ \\
\hline
\end{tabular}

Note-The values of all VI schedules are in minutes and are constructed from a constant probability progression /Catania \& Reynolds, 1968). Key color refers to the color of the food key during each component of the concurrent schedules. The notations $2 B$ and $3 B$ are used to distinguish these conditions from the second and third conditions (labeled $2 A$ and $3 A$ ) of Experi ment 1 . Condition 1 involved the same reinforcement contingencies in both experiments. over key response rates are plotted as a function of each phase in each condition (as in Experiment 1), food-key responding is plotted as a function of both phases (assessing absolute rate changes) and relative response rate (assessing the relationship between absolute and relative responding) in each condition. Particulars are delineated below.

Food-key responding during the unaltered component of the multiple schedule. Figure 3 shows absolute rate of responding on the food key as a function of phases and the logarithm of the proportion of responses allocated to each alternative in the unaltered component. Each data point represents the mean of the last 15 sessions of each phase and is denoted by the number in parentheses next to the appropriate point; the three conditions are numbered consecutively from left to right (represented by circles, triangles, and squares, respectively), with the schedule of reinforcement operating in the unaltered component also noted.

Absolute rates. For an examination of the behavioral contrast effects obtained in Experiment 2, Figure 3 presents the data obtained during baseline (Phase 1) and return-to-baseline phases (Phase 3), as indicated by the open points, with the data obtained during the manipulation phase (Phase 2), as indicated by the closed data points in each condition (we return to these same data with regard to relative measures below).

During Condition 1, a conc VI 2.4-min VI 2.4-min schedule was in effect, and all four subjects showed very stable responding during the terminal sessions of this phase (again, these data are not shown). In Phase 2, all four birds significantly increased their responding above baseline levels during presentations of the unaltered component; three birds significantly reduced their responding in Phase 3, while B-3927 showed a significant increase.

In Condition 2B, a conc VI 2-min VI 3-min schedule was programmed in the unaltered component and responding during the terminal sessions of baseline was very stable. In Phase 2 , all four birds significantly increased their responding above baseline levels. In Phase 3, all birds showed a decrease except that the decline exhibited by B-5926 was not statistically significant.

In Condition 3B, a conc VI 1.5-min VI 6-min schedule was arranged in the unaltered component and all four birds exhibited fairly stable responding during the baseline phase of this condition. In Phase 2 all birds showed a significant increase in responding during the unaltered component and a significant decrease during Phase 3.

Relative behavior. For an examination of the relationship between absolute and relative behavior, Figure 3 presents absolute rates as a function of the relative rates obtained during the three phases of each condition. If absolute behavior were positively correlated with relative behavior, then the filled points 


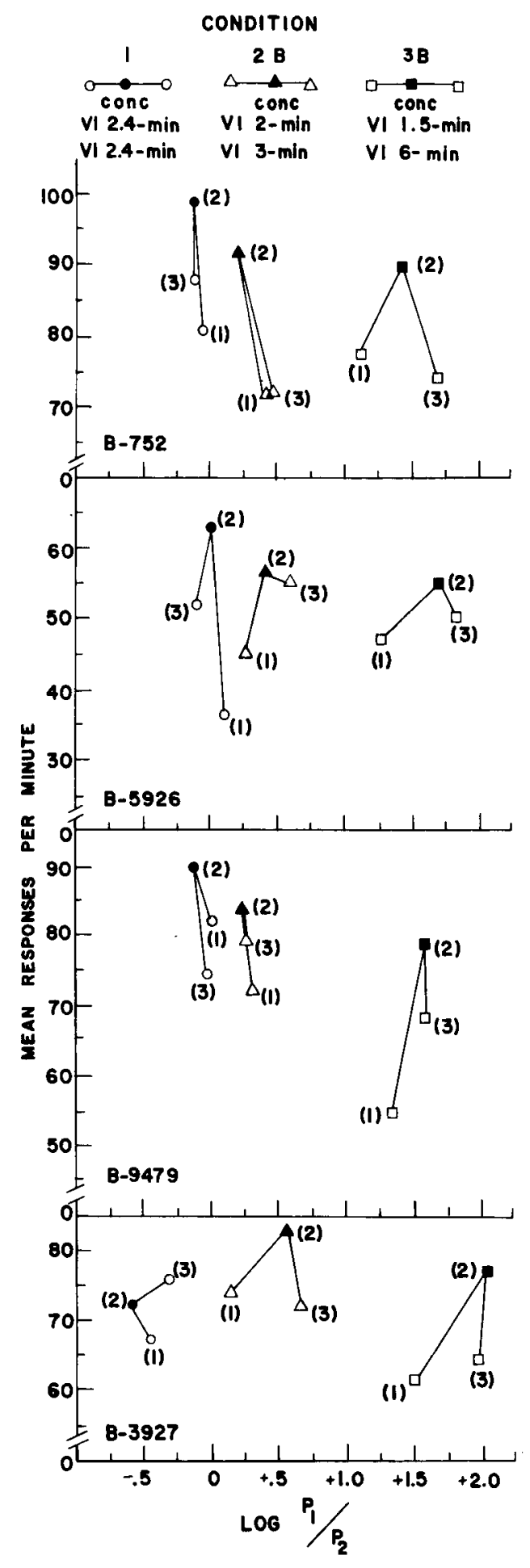

Figure 3. Average overall rate of responding on the food key during the unaltered component of the multiple schedule plotted as a function of (phases) and the proportion of responses in that component. These averaged points are from the last 15 sessions of each phase for each bird. The schedule of reinforcement during the unaltered component is noted for each condition.

representing Phase 2 would consistently be displaced to the right-outside the range of relative behaviors established during Phases 1 and 3 of each condition. On the other hand, if these types of behaviors were correlated in a negative fashion, the Phase 2 value would then be displaced to the extreme left of the range of these baseline distributions. Close examination of these data reveals that no systematic changes in relative behavior occurred as absolute rates changed (i.e., no systematic pattern of displacement emerges) when extinction was introduced during presentations of the altered component in Phase 2. In most cases, the points representing Phase 2 fall within the prescribed range of values, indicating that these behaviors are independent.

Changeover-key responding during the unaltered component of the multiple schedule. Figure 4 shows the average rate of changeovers during the last 15 sessions of each phase in each condition. During Condition 1, a conc VI 2.4-min VI 2.4-min schedule was programmed in the unaltered component. None of the birds exhibited any systematic increases prior to the experimental manipulation. In Phase 2 , all birds significantly increased their changeover rates above baseline; this was subsequently followed by a significant decrease in responding during Phase 3.

In Condition 2B, a conc VI 2-min VI 3-min schedule was programmed in the unaltered component and none of the birds showed any systematic increases during baseline training. During Phase 2, three birds significantly increased their changeover rates while B-3927 showed a significant decrease. In Phase 3, B-752 and B-3927 showed a significant decrease in changeover rates while B-5926 and B-9479 did not.

In Condition 3B, a conc VI 1.5-min VI 6-min schedule was arranged in the unaltered component of the multiple schedule. No trends were evident during the terminal sessions of baseline training, and in Phase 2 only B-9479 showed a significant increase in changeover response rates. Three birds did show a significant decrease in changeover rates in Phase 3, while the remaining subject, B-3927, showed no changes across the three phases in Condition 3B.

\section{GENERAL DISCUSSION}

The primary purpose of the present investigation was to determine if the relative strength of behavior between two response alternatives is affected when changes occur in the absolute strength of these behaviors in the form of behavioral contrast effects. Experiment 2 showed that despite increases in absolute responding to each alternative in the unaltered component of the multiple schedule (i.e., contrast), the proportion of keypecks allocated to these alternatives remained invariant (i.e., matching was maintained). This finding is commensurate with previous results (Herrnstein, 1961; Holz, 1968; McSweeney, 1975, 1977; Wald \& Cheney, 1975) obtained under other types of situations and employing different experimental manipulations. Taken together, this body of research supports the notion that absolute and rela- 


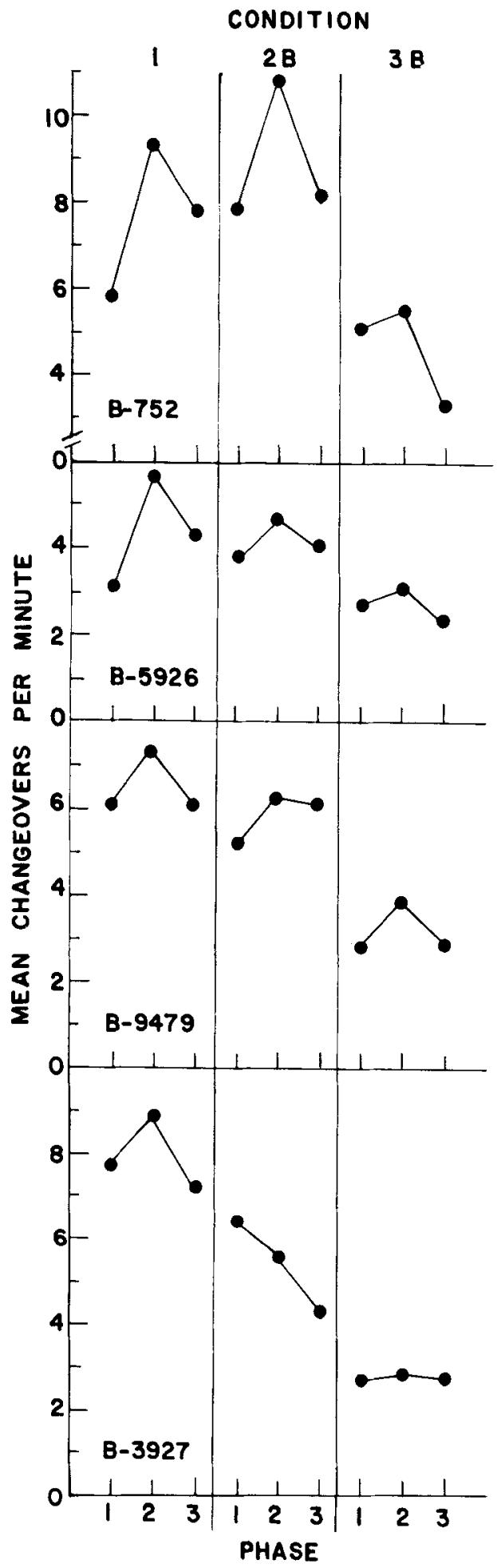

Figure 4. Average overall rate of responding on the changeover key during the unaltered component of the multiple schedule during the last 15 sessions of each phase for each bird.

tive strengths of behavior are independent of one another as implicated by various forms of the matching law (e.g., Baum \& Rachlin, 1969; Herrnstein, 1961, 1970).

Experiment 2 showed that the proportion of responses allocated to the response alternatives in the unaltered component of the multiple schedule was unaffected when the reinforcement contingencies associated with the other component were changed from VI reinforcement to extinction. Just after the present data were collected, Nevin, Mandell, and Whittaker (1978) reported a study in which changes in reinforcement contingencies associated with one component of a multiple schedule did indeed affect the proportion of responses allocated to the behavioral alternatives in the other component, that is, contrast occurred differentially. Nevin et al. interpreted their results as consistent with Nevin's (1974) view regarding response strength as the resistance of responding to change. That perspective assumes that the higher the reinforcement frequency for responding, the greater the strength of that response, and hence, the more resistant it is to change. Similarly, the lower the frequency of reward for responding, the less response strength accrues and the more susceptible it (the behavior) is to change. It follows, therefore, that when unequal densities of reinforcement are associated with concurrently available alternatives in the unaltered component of the multiple schedule, shifts in behavioral allocation (or differential contrast effects) should be observed because of differential tendencies for these behaviors to change. As can be seen, this accurately describes the Nevin et al. findings. However, this position has difficulty accounting for the fact that contrast occurred in equal proportions during Conditions $2 \mathrm{~B}$ and $3 \mathrm{~B}$ of the present study. In order to resolve this conflict, other possible alternatives must be examined. Given the very viable notion that different procedures might produce different types of behavioral contrast (see de Villiers, 1977; Schwartz \& Gamzu, 1977), it seems plausible at this time to assume that the type of contrast obtained by Nevin et al. was a different type of contrast from that obtained in the present study simply because of the many procedural differences in the two studies (e.g., Nevin et al. used a discrete-trial procedure and sophisticated birds, while the present research employed a free-operant procedure and naive birds). It should be further pointed out that Nevin's (1974) notion of response strength "does not specify the factors responsible for contrast; rather it groups contrast together with a variety of operations including extinction, satiation, and conditioned suppression and notes some commonalities among their behavioral effects" (Nevin et al., 1978, p. 60). Given this view, it is possible that the type of contrast observed by Nevin et al. does indeed have a great deal in common with the behavioral effects of those conditions specified above, while the contrast effects observed in the present investigation do not. Unfortunately, confirmation of this explanation must wait until further research delineates the various types of contrast if, in fact, they exist.

As mentioned earlier, one dependent variable that may be examined in concurrent schedules is the rate 
at which subjects change from one component to another. It was further noted that by manipulating certain contingencies associated with the components of the concurrent schedule, the frequency of changeovers between those components may be affected. For example, Herrnstein (1961) observed that the number of changeovers between two components decreased in a linear fashion as the difference in percentage of reinforcement arranged by those components increased. Experiment 2 of the present study revealed similar findings when the difference in percentage of reinforcement delivered by the components of the concurrent schedule was increased to about $60 \%$ (Condition 3B); rate of changeovers between those components decreased relative to the frequency of changeovers exhibited when the difference was $20 \%$ or less (Conditions 1 and 2B; see Figure 4). Moreover, Herrnstein employed the twokey concurrent procedure, while we used the changeover-key procedure. Since both procedures yielded similar patterns of changeover behavior, Catania's (1966) previous assumption that the two procedures are formally and functionally equivalent is supported.

The second purpose of the present investigation was to determine if changeover behavior was subject to the contrast phenomenon, as suggested by previous research (Catania, 1961; Marcattilio \& Richards, 1976). The data presented in Figures 2 and 4 reveal that changing the schedule of reinforcement in the altered component of the multiple schedule does, indeed, affect the frequency of changeovers during the unaltered component. However, these effects were evident only under certain reinforcement contingencies. When, in Experiment 1, the VI schedules associated with each component of the concurrent schedule were of equal value, positive changeover contrast occurred if the overall rate of reinforcement in the unaltered component and altered component (during Phases 1 and 3) was high (i.e.,Conditions 2 and $3 \mathrm{~A}$ ) but not if it was low (i.e., Condition 2A). There was also a marked failure to observe positive changeover contrast when unequal concurrent reinforcement densities were programmed during Conditions 2B and 3B of Experiment 2. It should be noted, however, that such findings may be restricted only to those situations in which the changeover response is reinforced according to a continuous reinforcement schedule and, as in the present study, the COD duration is on the order of 2 sec. Thus, before a reasonable hypothesis explaining these findings is advanced, it would seem that more parametric data is needed specifying the conditions under which changeover contrast occurs.

Analyses of such data would be of even further importance since the results of the present study also suggest that changeover contrast and food-key contrast are independent to a certain degree. Table 3 summarizes the type of effect obtained for each bird
Table 3

Type of Effect Found for Each Bird in Each Experiment Across Conditions

\begin{tabular}{|c|c|c|c|c|}
\hline & & Condition 1 & Condition 2 & Condition 3 \\
\hline \multicolumn{5}{|c|}{ Experiment 1} \\
\hline B-2855 & $\begin{array}{l}\text { FK } \\
\text { CO-K }\end{array}$ & $\begin{array}{l}\text { Contrast } \\
\text { Contrast }\end{array}$ & $\begin{array}{l}\text { Induction } \\
\text { Induction }\end{array}$ & $\begin{array}{l}\text { Contrast } \\
\text { Contrast }\end{array}$ \\
\hline B-716 & $\begin{array}{l}\text { FK } \\
\text { CO-K }\end{array}$ & $\begin{array}{l}\text { Contrast } \\
\text { Contrast }\end{array}$ & $\begin{array}{l}\text { Contrast } \\
\text { No Effect }\end{array}$ & $\begin{array}{l}\text { Contrast } \\
\text { Contrast }\end{array}$ \\
\hline B-1900 & $\begin{array}{l}\text { FK } \\
\text { CO-K }\end{array}$ & $\begin{array}{l}\text { Contrast } \\
\text { Contrast }\end{array}$ & $\begin{array}{l}\text { Induction } \\
\text { No Effect }\end{array}$ & $\begin{array}{l}\text { Contrast } \\
\text { Contrast }\end{array}$ \\
\hline B-4310 & $\begin{array}{l}\text { FK } \\
\text { CO-K }\end{array}$ & $\begin{array}{l}\text { Contrast } \\
\text { Contrast }\end{array}$ & $\begin{array}{l}\text { No Effect } \\
\text { Contrast }\end{array}$ & $\begin{array}{l}\text { Induction } \\
\text { Contrast }\end{array}$ \\
\hline \multicolumn{5}{|c|}{ Experiment 2} \\
\hline B-752 & $\begin{array}{l}\text { FK } \\
\text { CO-K }\end{array}$ & $\begin{array}{l}\text { Contrast } \\
\text { Contrast }\end{array}$ & $\begin{array}{l}\text { Contrast } \\
\text { Contrast }\end{array}$ & $\begin{array}{l}\text { Contrast } \\
\text { No Effect }\end{array}$ \\
\hline B-5926 & $\begin{array}{l}\text { FK } \\
\text { CO-K }\end{array}$ & $\begin{array}{l}\text { Contrast } \\
\text { Contrast }\end{array}$ & $\begin{array}{l}\text { No Effect } \\
\text { No Effect }\end{array}$ & $\begin{array}{l}\text { Contrast } \\
\text { No Effect }\end{array}$ \\
\hline B-9479 & $\begin{array}{l}\text { FK } \\
\text { CO-K }\end{array}$ & $\begin{array}{l}\text { Contrast } \\
\text { Contrast }\end{array}$ & $\begin{array}{l}\text { Contrast } \\
\text { No Effect }\end{array}$ & $\begin{array}{l}\text { Contrast } \\
\text { Contrast }\end{array}$ \\
\hline B-3927 & $\begin{array}{l}\text { FK } \\
\text { CO-K }\end{array}$ & $\begin{array}{l}\text { Induction } \\
\text { Contrast }\end{array}$ & $\begin{array}{l}\text { Contrast } \\
\text { Induction }\end{array}$ & $\begin{array}{l}\text { Contrast } \\
\text { No Effect }\end{array}$ \\
\hline
\end{tabular}

Note-See text for details.

in both experiments across conditions with regard to pecking the food key (FK) and changeover key (CO-K). Behavioral contrast was considered to have occurred if there was a statistically significant increase in responding during the unaltered component in Phase 2 followed by a statistically significant decrease in responding back towards baseline during Phase 3 . Induction was considered to be any significant behavioral change in the unaltered component that was in the same direction as response rates and reinforcement contingencies in the altered component (i.e., a decrease in Phase 2 and/or an increase in Phase 3). Finally, if no statistically significant change in responding occurred during either Phase 2 or Phase 3, the term "no effect" was entered. The most striking aspect of Table 3 is that there is a difference between Experiments 1 and 2 with regard to the amount of covariation of food-key contrast and changeoverkey contrast. A contingency coefficient revealed that the degree of covariation between the two effects was significant according to a chi-square test of independence $\left(C=.53 ; \chi^{2}=4.70, \mathrm{df}=2, \mathrm{p}<.05\right)$ in Experiment 1. However, the degree of covariance between these effects observed in Experiment 2 was not significant $\left(\mathrm{C}=.41 ; \chi^{2}=2.36, \mathrm{df}=2, \mathrm{p}>\right.$ $.20)$. Moreover, the only conditions (in both experiments) in which effects occurred coincidently was when a conc VI 2.4-min VI 2.4-min schedule was programmed (Conditions 1 and $3 \mathrm{~A}$ ). On this basis, one might suspect that many interacting factors determine whether one or the other or even both types of behavioral contrast would be observed, especially when unequal concurrent reinforcement densi- 
ties are programmed in the unaltered component of the multiple schedule (Conditions $2 \mathrm{~B}$ and $3 \mathrm{~B}$ of Experiment 2). The mult conc conc procedure, as used in the present investigation, as well as modifications of the procedure seems to be a viable paradigm to employ in order to verify the above notion.

In summary, the present investigation demonstrated that relative behavior (i.e., matching) is not disrupted when contrast occurs, that these contrast effects are only obtained when the overall frequency of reinforcement in the unaltered component of the multiple schedule is high, that changeover contrast occurs under certain contingencies of reinforcement, and that food-key contrast and changeover contrast are independent phenomena.

\section{REFERENCE NOTE}

1. Marcattilio, A. J., \& Richards, R. W. Interactions in multiple (concurrent) (concurrent) schedules of reinforcement. Paper presented at Rocky Mountain Psychological Association, Phoenix, Arizona, 1976.

\section{REFERENCES}

Baum, W. M., \& RAchlin, H. C. Choice as time allocation. Journal of the Experimental Analysis of Behavior, 1969, 12, 861-874.

Bilbrey, J., \& Winokur, S. Behavioral contrast in a second order multiple schedule of reinforcement. Bulletin of the Psychonomic Society, 1974, 4, 206-208.

Bloomfield, T. M. Behavioral contrast and the peak shift. In R. M. Gilbert \& W. S. Sutherland (Eds.), Animal discrimination learning. London: Academic Press, 1969.

Brownstein, A. J., \& Pliskoff, S. S. Some effects of relative reinforcement rate and changeover delay on response-independent concurrent schedules of reinforcement. Journal of the Experimental A nalysis of Behavior, 1968, 11, 683-688.

Catania, A. C. Behavioral contrast in a multiple and concurrent schedule of reinforcement. Journal of the Experimental Analysis of Behavior, 1961, 4, 335-342.

Catania, A. C. Concurrent operants. In W. K. Honig (Ed.), Operant behavior: Areas of research and application. New York: Appleton-Century-Crofts, 1966.

Catania, A. C., \& Reynolds, G. S. A quantitative analysis of responding maintained by interval schedules of reinforcement. Journal of the Experimental Analysis of Behavior, 1968, 11, 327-383.

de Villie rs, $P$. Choice in concurrent schedules and a quantitative formulation of the law of effect. In W. K. Honig \& J. E. R. Staddon (Eds.), Handbook of operant conditioning. Englewood Cliffs, N.J: Prentice-Hall, 1977.

Findley, J. D. Preference and switching under concurrent scheduling. Journal of the Experimental Analysis of Behavior, 1958 , 1, 123-144.

Herrnstein, R. J. Relative and absolute strength of response as a function of frequency of reinforcement. Journal of the Experimental A nalysis of Behavior, 1961, 4, 267-272.
Herrnstein, R. J. On the law of effect. Journal of the Experimental A nalysis of Behavior, 1970, 13, 243-266.

Hinson, J. M., \& Staddon, J. E. R. Behavioral competition: A mechanism for schedule interactions. Science, 1978, 202, $432-434$.

Holz, W. C. Punishment and rate of positive reinforcement. Journal of the Experimental Analysis of Behavior, 1968, 11, 285-292.

McSweeny, F. K. Concurrent schedule responding as a function of body weight. Animal Learning \& Behavior, 1975, 3, 264-270.

McSweEny, F. K. Sum of responding as a function of sum of reinforcement on two-key concurrent schedules. Animal Learning \& Behavior, 1977, 5, 110-114.

Nevin, J. A. Response strength in multiple schedules. Journal of the Experimental Analysis of Behavior, 1974, 21, 389-408.

Nevin, J. A., Mandell, C., \& Whittaker, S. Contrast and induction in multiple schedules of discrete-trial concurrent reinforcement. Journal of the Experimental Analysis of Behavior, $1978,30,53-61$.

Pliskoff, S. S., \& Green, D. Effects on concurrent performances of a stimulus correlated with reinforcer availability. Journal of the Experimental Analysis of Behavior, 1972, 17, 221-227.

Premack, D. On some boundary conditions of contrast. In J. Tapp (Ed.), Reinforcement and behavior. New York: Academic Press, 1969.

REYNOLDs, G. S. Behavioral contrast. Journal of the Experimental Analysis of Behavior, 1961, 4, 57-71.

Reynolds, G. S. Some limitations on behavioral contrast and induction during successive discrimination. Journal of the Experimental Analysis of Behavior, 1963, 6, 131-139.

Schwartz, B., \& Gamzu, E. Pavlovian control of operant behavior: An analysis of autoshaping and its implications for operant conditioning. In W. K. Honig \& J. E. R. Staddon (Eds.), Handbook of operant conditioning. Englewood Cliffs, N.J: Prentice-Hall, 1977.

Spealman, R. D., \& Gollub, L. R. Behavioral interactions in multiple variable-interval schedules. Journal of the Experimental Analysis of Behavior, 1974, 22, 471-481.

Shull, R. L., \& Pliskoff, S. S. Changeover delay and concurrent schedules: Some effects on relative performance measures. Journal of the Experimental Analysis of Behavior, 1967, 10, $517-527$.

Shull, R. L., \& Pliskoff, S. S. Changeover behavior under pairs of fixed-ratio and variable-ratio schedules of reinforcement. Journal of the Experimental Analysis of Behavior, 1971, 16, 75-79.

Terrace, H. S. By products of discrimination learning. In G. H. Bower (Ed.), The psychology of learning and motivation, $V$. New York: Academic Press, 1972.

Todorov, J. C. Concurrent performances: Effect of punishment contingent on the switching response. Journal of the Experimental Analysis of Behavior, 1971, 16, 51-62.

Wald, B. A., \& Cheney, C. D. Matching behavior and deprivation. Bulletin of the Psychonomic Society, 1975, 6, 4-6.

Wilton, R. N., \& GaY, R. A. Behavioral contrast in one component of a multiple schedule as a function of the reinforcement conditions operating in the following component. Journal of the Experimental Analysis of Behavior, 1969, 12, 239-246.

(Received for publication February 2, 1979; revision accepted May $31,1979$. 